\title{
40 ANOS DE TRANSPLANTE DE CÉLULAS-TRONCO HEMATOPOIÉTICAS: DA ORIGEM METODOLÓGICA À PRÁTICA CLÍNICA
}

\author{
40 years of transplantation of hematopoietic stem cells: from the methodological origin to \\ clinical practice.
}

\author{
Maicon Presser Cigolini', Juliana Tonietto Zampieri', Mario Sergio Fernandes²
}

\begin{abstract}
RESUMO
Objetivo: Explorar o transplante de células-tronco hematopoiéticas na prática clínica contemporânea, com abordagem multidisciplinar no que tange às especialidades médicas. Método: A revisão incluiu pesquisa no acervo da biblioteca da Pontifícia Universidade Católica do Rio Grande do Sul, além de pesquisa na base de dados Medline, a partir dos descritores: transplante de medula óssea, células-tronco hematopoiéticas, leucemia, linfoma, doença enxerto contra hospedeiro, efeito antileucêmico, irradiação corporal total, antígenos de histocompatibilidade. Conclusão: O transplante de células progenitoras hematopoiéticas é uma prática consagrada na medicina há algumas décadas; apesar disso, ainda são muitos os desafios que permeiam o sucesso dessa terapêutica, o que envolve compreensão a respeito da indicação, da técnica de procedimento e do acompanhamento pós-transplante, bem como do incentivo à doação. Permeada por questões complexas, que transitam do âmbito bioético, imunológico e clínico, exige do médico, independente de sua especialidade, conhecimento a respeito do tema.
\end{abstract}

Descritores: Transplante; Células-Tronco Hematopoiéticas; Medula Óssea; Antígenos de Histocompatibilidade; Doença EnxertoHospedeiro.

\begin{abstract}
Instituições:
1. Faculdade de Medicina. Pontifícia Universidade Católica do Rio Grande do Sul, Porto Alegre-RS.

2. Departamento de Medicina Interna. Faculdade de Medicina. Pontifícia Universidade Católica do Rio Grande do Sul, Porto Alegre-RS.
\end{abstract}

\section{Correspondência:}

Maicon Presser Cigolini

Av. Clemenciano Barnasque, 160 / 502, CEP 91720-260, Porto Alegre/RS.

Telefone: (51) 8274-8957

E-mail: maiconcigolini@gmail.com
Aceito em: 07.07.11

\section{INTRODUÇÃO}

O transplante de células-tronco hematopoiéticas pode ser curativo para selecionadas doenças malignas e não-malignas. ${ }^{1-13} \mathrm{~A}$ prática consiste na substituição da medula afetada por células normais de medula óssea, através do enxerto de células progenitoras hematopoiéticas - as quais poderão ter origem da medula óssea, do sangue periférico ou do cordão umbilical.

Foi Donnal Thomas, no ano de 1969 em Seattle (EUA), que realizou o primeiro transplante de medula óssea (TMO) alogênico bem sucedido em um paciente com leucemia aguda, após tê-lo submetido à irradiação corporal total (ICT), seguida da infusão de medula óssea HLA idêntica, retirada do irmão do paciente. ${ }^{14}$ Esse trabalho rendeu a Thomas o Nobel de Medicina de 1990. No Brasil, o Serviço de Hematologia da Universidade Federal do Paraná (com o hematologista Ricardo Pasquini), foi responsável pelo primeiro TMO do país, em 1979. Desde então, enormes avanços ocorreram, tornando a medida uma prática comum na medicina. Células-tronco hematopoiéticas transplantadas resultam em maior cura e remissão da doença, entretanto também estão associadas a grande morbidade e, eventualmente, mortalidade. Dessa forma, a indicação dessa terapêutica envolve uma importante análise a respeito da doença e do quadro clínico do paciente. O presente artigo de revisão pretende explorar os conceitos contemporâneos que envolvem o transplante de células-tronco hematopoiéticas (TCTH) e os avanços que permeiam a clínica, dos quais todo médico deve ter conhecimento. 


\section{MÉTODO}

Esta revisão incluiu pesquisa no acervo da Biblioteca Central e da Biblioteca da Faculdade de Medicina da Pontifícia Universidade Católica do Rio Grande do Sul, além de pesquisa na base de dados Medline, a partir dos descritores: transplante de medula óssea, células-tronco hematopoiéticas, leucemia, linfoma, doença enxerto contra hospedeiro, efeito antileucêmico, irradiação corporal total, antígenos de histocompatibilidade.

\section{TIPOS DE TRANSPLANTE}

\section{Transplante Alogênico}

No TMO alogênico, as células progenitoras hematopoiéticas têm origem em qualquer doador, excluindo, entretanto, o próprio receptor ou gêmeo monozigótico. Uma vez que o procedimento envolve uma série de riscos (funcionalidade do enxerto, rejeição e possíveis complicações), a necessidade de sua realização fundamenta-se em sua superioridade em relação às outras terapêuticas disponíveis ou após o fracasso de terapias iniciais. O transplante alogênico tornou-se possível no início dos anos 1960, com a identificação e classificação do HLA (complexo de histocompatibilidade maior). ${ }^{15,16}$ A grande vantagem dessa modalidade é que a medula transplantada está isenta de contaminação tumoral. Por outro lado, há alto risco de ocorrência de doença enxerto contra hospedeiro $(\mathrm{DECH})$ e de falência medular. Uma possível incompatibilidade maior no sistema $\mathrm{ABO}$ não consiste em barreira para execução de TMO. A medula óssea pode sofrer uma técnica de deseritrocitação ou o paciente ser submetido à plasmaférese para a retirada das isohemaglutininas, permitindo a infusão da medula óssea. ${ }^{17}$

\section{Transplante Autólogo}

Em algumas situações clínicas, é possível utilizar a medula ou sangue periférico do próprio receptor. Estudos nos anos 1980 mostraram que o transplante autólogo curou alguns linfomas, após a quimioterapia convencional ter falhado. ${ }^{18}$

Essa modalidade, evidentemente, é mais restrita que o transplante alogênico, e o material para transfusão deve estar livre de qualquer contaminação por células malignas. Em virtude disso, é recomendado para doenças adquiridas, nas quais a função das células-tronco hematopoiéticas esteja intacta, como neuroblastoma, melanoma metastático, mieloma múltiplo, doença de Hodgkin, linfoma de Burkitt, sarcoma de Ewing, carcinoma de ovário, testículos e mamas. Para assegurar que células potencialmente malignas não sejam posteriormente infundidas, ao ser retirada a medula, são tratadas por métodos físicos, farmacológicos e imunológicos.

A despeito de não haver qualquer problema relativo à rejeição do enxerto, o risco de recidiva da doença de origem é bastante importante. Contudo, uma vez que o transplante autólogo exclui a $\mathrm{DECH}$, a prática pode ser adotada para tratamento de pacientes mais idosos. A mortalidade é consideravelmente menor nessa modalidade de transplante, mas o efeito antitumor do enxerto é reduzido. Após o TMO autólogo, quando houve óbitos, a doença primária respondeu por mais de $70 \%$ do número total deles. ${ }^{19}$

\section{FONTE DAS CÉLULAS-TRONCO HEMATOPOIÉTICAS}

É possível realizar a terapêutica com células da medula óssea, células-tronco do sangue periférico, células de sangue do cordão umbilical, células do fígado fetal, células cultivadas e geneticamente modificadas. As células provenientes da medula óssea são obtidas por meio de múltiplas punções, geralmente nas cristas ilíacas, com o paciente anestesiado. Todavia, desde o início da década de 1990, as célulastronco periféricas - colhidas por aférese após a mobilização com fatores de crescimento de colônias de granulócitos (G-CSF) - têm sido largamente utilizadas como fonte de células progenitoras hematopoiéticas para o transplante autólogo e levam à recuperação medular mais rapidamente em comparação com a medula óssea. ${ }^{20}$ A prática também vem sendo empregada para transplantes alogênicos, e os resultados têm tido semelhança. No entanto, ainda há dúvidas sobre qual a melhor fonte de células-tronco, uma vez que inúmeros fatores devem ser considerados a fim de garantir os melhores resultados. ${ }^{21}$

Em relação à recaída, estudos não mostraram diferença entre as duas fontes de células progenitoras. Alguns trabalhos, todavia, relataram algum benefício para o uso de células-tronco periféricas, que poderiam apresentar menor risco de recaída ou menor risco de apresentar doença residual mínima. ${ }^{22-26}$

Alguns aspectos de suma importância devem ser levados em conta a respeito das duas modalidades. Embora existam mais células $\mathrm{T}$ nas células-tronco periféricas, não houve diferença a respeito da incidência de DECH aguda, em comparação com o uso de medula óssea; contudo, os casos de DECH crônica são mais comuns naqueles que utilizam as células periféricas. Quanto à sobrevida, estudos sugerem melhores resultados em curto prazo com o uso de células-tronco periféricas, mas não existem dados conclusivos em longo prazo. Por questões de facilidades logísticas e preferência dos doadores, o uso de células periféricas vem sendo empregado cada vez mais. Entretanto, essa decisão deve ser entendida na individualidade de cada paciente..$^{22,26,27}$

Nas duas últimas décadas, o transplante de células-tronco hematopoiéticas utilizando sangue proveniente de cordão umbilical teve importante aumento, particularmente nos pacientes pediátricos. ${ }^{28-37} \mathrm{O}$ inconveniente é o volume que pode ser extraído (entre 50 e $200 \mathrm{ml}$, em geral). Por esse motivo, o número de células nucleadas é habitualmente suficiente apenas para pacientes com menos de $30 \mathrm{~kg}$ de peso. ${ }^{19}$ A reconstituição medular é lenta e infecções são comuns logo no pós-transplante. Menor compatibilidade HLA é necessária porque há menor ocorrência de DECH, com a ação antitumor do enxerto mantida.

\section{INDICAÇÕES}

O TMO é indicado para doenças em que existe falência do sistema hematopoiético, seja por infiltração de células leucêmicas na medula óssea, por doenças que alterem a produção dos constituintes sanguíneos ou por doenças que comprometem gravemente o sistema imunológico, conforme exposto na Tabela $1 .{ }^{38-40}$

\section{Doenças Auto-imunes}

Em meados de 1990, começaram-se a organizar diversos protocolos ao redor do mundo, com o intuito de utilizar o TCTH para tratamento de doenças auto-imunes. Vários centros começaram a transplantar pacientes com doença grave e refratária à terapia convencional com células-tronco autólogas, depletadas de linfócitos T e B. A partir de 2000, quando ocorreu um Workshop internacional em Ribeirão Preto, decidiu-se iniciar um projeto piloto de TCTH em doenças auto-imunes, cooperativo, de âmbito nacional, coordenado pelo Centro de Terapia Celular/FAPESP do Hemocentro Regional de Ribeirão Preto. 
Desde então, têm-se realizado estudos no tratamento de Diabetes Mellitus 1, esclerose múltipla, lúpus eritematoso sistêmico, entre outras enfermidades de etiologia auto-imune. Embora se tenha conseguido resultados animadores em grupos selecionados, a recorrência da doença segue como o maior desafio para o emprego dessa modalidade de tratamento. A despeito de existirem diversos protocolos para regimes de condicionamento, ainda não existem estudos suficientes para indicar quais as opções que garantem melhores resultados no controle da doença e menores taxas de recidiva e comorbidades. ${ }^{41,42}$

Tabela 1 - Doenças que podem ser tratadas com transplante de células-tronco

\begin{tabular}{|c|c|c|c|}
\hline \multicolumn{2}{|r|}{ Transplante autólogo } & \multicolumn{2}{|r|}{ Transplante alogênico } \\
\hline \multirow{10}{*}{ Câncer } & Mieloma múltiplo & \multirow{10}{*}{ Câncer } & Leucemia mielóide aguda \\
\hline & Linfoma não-Hodgkin & & Leucemia linfoblástica aguda \\
\hline & Linfoma Hodgkin & & Leucemia mielóide crônica \\
\hline & Leucemia mielóide aguda & & Síndromes mielodisplásicas \\
\hline & Neuroblastoma & & Desordens mieloproliferativas \\
\hline & Câncer ovariano & & Linfoma não-Hodgkin \\
\hline & \multirow{4}{*}{$\begin{array}{l}\text { Tumor de células } \\
\text { germinativas }\end{array}$} & & Linfoma Hodgkin \\
\hline & & & Leucemia linfocítica crônica \\
\hline & & & Mieloma múltiplo \\
\hline & & & Leucemia mielóide crônica juvenil \\
\hline \multirow{6}{*}{$\begin{array}{l}\text { Outras } \\
\text { doenças }\end{array}$} & \multirow{6}{*}{$\begin{array}{l}\text { Doenças auto-imunes } \\
\text { Amiloidose }\end{array}$} & \multirow{6}{*}{$\begin{array}{l}\text { Outras } \\
\text { doenças }\end{array}$} & $\begin{array}{l}\text { Hemoglobinúria paroxística } \\
\text { noturna } \\
\text { Anemia de Fanconi }\end{array}$ \\
\hline & & & Anemia aplástica \\
\hline & & & Anemia de Blackfan-Diamond \\
\hline & & & Talassemia maior \\
\hline & & & $\begin{array}{l}\text { Anemia falciforme } \\
\text { Imunodeficiência combinada } \\
\text { severa } \\
\text { Síndrome de Wiskott-Aldrich }\end{array}$ \\
\hline & & & Erros inatos do metabolismo \\
\hline
\end{tabular}

\section{PROCEDIMENTO}

Para avaliar a histocompatibilidade maior (HLA), são tipados os loci A, B, C e DR do cromossomo 6 humano; sem essa histocompatibilidade, as chances de sucesso do TMO são mínimas devido à grande possibilidade de ocorrer $\mathrm{DECH} .{ }^{43}$ Quanto à cultura mista de leucócitos, as células do receptor não devem exibir resposta proliferativa aos linfócitos do doador (teste não-reagente) e, se o HLA for idêntico, o par doador-receptor é considerado compatível.

Após ser definido o doador, a etapa seguinte consiste na preparação do receptor, o qual tem sua medula óssea atacada por quimioterapia, em doses que seriam habitualmente maciças, combinadas com irradiação corporal total ou parcial, tornando-a aplásica. Irradiação total fracionada (uso de doses menores) em associação com ciclofosfamida é o padrão de preparação desde os anos 1980. Especialmente a partir da década de 1990, outros sistemas de preparação vêm sendo utilizados, associando doses menores de irradiação com drogas quimioterápicas. ${ }^{44}$ Esse regime ocorre um dia antes do transplante e tem como objetivo imunossuprimir e remover células indesejáveis do organismo, podendo ter acrescidos agentes antineoplásicos para remover células anormais que podem ser benignas, como no caso da talassemia.
O doador é submetido à anestesia geral em centro cirúrgico, quando doa células diretamente da medula óssea. Os locais mais comuns de aspiração são a crista ilíaca posterior, crista ilíaca anterior, o esterno e a tíbia. São colhidos de 10 a $15 \mathrm{ml}$ de medula óssea por $\mathrm{kg}$ do receptor. A medula óssea colhida é filtrada e, em seguida, acondicionada em bolsas coletoras de sangue sem conservante, para imediata transfusão endovenosa ou processamento futuro e estocagem apropriada.

O dia da transfusão é considerado o dia zero e, aproximadamente 14 dias após o transplante, são perceptíveis sinais de que a medula transplantada está em funcionamento normal (a chamada "pega"). A recuperação do sistema imunológico ocorre gradual e progressivamente, completando-se no sexto mês após o transplante, mas pode prolongar-se em pacientes que desenvolveram $\mathrm{DECH}$ crônica.

A funcionalidade do enxerto ocorre em mais de $95 \%$ dos pacientes e a sua rejeição é raramente observada (mais comum nas anemias aplásticas associadas a regimes condicionantes menos agressivos ou quando há algum grau de incompatibilidade HLA). ${ }^{19}$ Vencida essa etapa, a principal preocupação corresponde a evitar a $\mathrm{DECH}$, que pode manifestar-se aguda ou cronicamente.

A mortalidade em virtude da doença primária, da DECH, de pneumonite intersticial, de infecções e de falência de órgãos está entre as causas mais frequentes de óbitos relativos ao TCTH. Todavia, a condição clínica pré-transplante está intimamente ligada à sobrevida e sucesso da terapêutica. Existe, ainda, o risco de neoplasias malignas (ocorre em 10\% dos casos) ou recidiva da doença primária, após o transplante.

\section{COMPLICAÇÕES}

O regime preparatório está associado a complicações antes do transplante, uma vez que a aplasia medular ocorre por meio de um agressivo ataque, seja de origem quimioterápica, por meio da radioterapia, ou ambos. Além disso, pancitopenia, associada ou não a infecções em atividade, fibrose hepática nos pacientes hipertransfundidos e comprometimento de outros órgãos tornam esses pacientes vulneráveis a inúmeras complicações. ${ }^{45}$

A lesão mais importante relacionada à toxicidade do regime de condicionamento é a DECH, mas outras lesões orgânicas estão associadas ao regime de condicionamento, como a insuficiência renal aguda secundária à lise tumoral ou por secreção anormal de ADH pelo uso de ciclofosfamida, de anfotericina $\mathrm{B}$, pela disfunção hepática ou sepse. ${ }^{46}$

A rejeição do enxerto está ligada a fatores clínicos da evolução da doença e de aspectos associados ao material enxertado (incompatibilidade HLA, depleção de células T, número de células infundidas insuficiente). Nos pacientes com doenças malignas, doador HLA inteiramente compatível, número ideal de células progenitoras hematopoiéticas e repleta de células $\mathrm{T}$, o índice de rejeição é inferior a 5\%. Já a recaída da doença maligna ocorre com maior freqüência em doenças de estágio avançado, acompanhada por um quadro clínico desfavorável e resistência prévia aos quimioterápicos. Pode-se infundir linfócitos do doador, o que pode levar à remissão ou até à cura da doença, embora esse efeito esteja intimamente ligado à sensibilidade das células malignas à ação citotóxica e também ao tipo de doença primária (na leucemia mielóide crônica, a eficácia seria de mais de $80 \%){ }^{46-48}$

Entre as complicações crônicas, encontram-se problemas pulmonares, complicações neuro-endócrinas, do crescimento e do 
desenvolvimento. As principais complicações estão descritas na Tabela $2 .{ }^{45}$

Tabela 2. Complicações do transplante de células-tronco hematopoiéticas.

\begin{tabular}{ll}
\hline Complicações imediatas (< 100 dias) & Complicações tardias (> 100 dias) \\
\hline Infecções (especialmente bacterianas, & Infecções (sobretudo varicela-zoster \\
fúngicas,Herpes simples, CMV*) & e bactérias encapsuladas) \\
Hemorragia & DEVH $\ddagger$ crônica (artrite, hepatite, escle- \\
DEVH $\ddagger$ aguda (pele, figado, TGl†) & rodermia, doença pulmonar e outros) \\
Falência do enxerto & Doença pulmonar crônica \\
Cistite hemorrágica & Doenças auto-imunes \\
Pneumonite intersticial & Catarata \\
Doença vaso-oclusiva e falência & Infertilidade \\
cardíaca & Malignidades secundárias
\end{tabular}

* citomegalovírus

$\dagger$ trato gastrintestinal

$\ddagger$ doença enxerto contra hospedeiro

\section{Doença do Enxerto Contra Hospedeiro}

A DECH foi reconhecida pela primeira vez em crianças com imunodeficiência combinada severa que inadvertidamente recebiam linfócitos alogênicos por transfusão sanguínea. De fato, ela pode ocorrer em qualquer situação em que células imunologicamente competentes ou seus precursores são transplantados em receptores imunologicamente deficientes, e as células transferidas reconhecem aloantígenos no hospedeiro. Trata-se, de fato, de uma resposta imune acentuada e - possivelmente estimulada - pela injúria resultante do regime usado na preparação pré-transplante. ${ }^{49}$

Na prática clínica, a DECH pode ser tão grave que os TMOs são feitos apenas entre doadores e receptores com HLA compatíveis. Entretanto, diferenças sutis podem ser suficientes para o desenvolvimento da doença e, mesmo com a tipagem realizada rotineiramente pré-transplante, sempre há risco do desenvolvimento da doença em transplantes alogênicos. O transplante realizado mediante células retiradas de doador não-aparentado está associado mais frequentemente com DECH mais severa ou com rejeição do enxerto. ${ }^{49-52}$

Classifica-se a DECH em "aguda" se ocorre em até três meses após o transplante e em "crônica" se ocorre após esse período. A forma aguda está relacionada à lesão tissular epitelial, induzida pelo regime de condicionamento, liberando várias citocinas inflamatórias (TNF e IL-1), aumentando a apresentação de antígenos HLA, moléculas de adesão e antígenos menores.

De acordo com a intensidade, gradua-se o quadro de 0 a IV (Tabela 3 ), estando os graus III e IV associados a altos índices de mortalidade. Idade mais avançada do receptor, incompatibilidade HLA, doador não-aparentado, intensidade do regime de condicionamento e doador do sexo feminino são fatores de risco e agravantes para a doença. A imunoprofilaxia é obrigatória, utilizando-se diversas associações de quimioterápicos. O manejo em quadros grau I e
II é feito, inicialmente, com corticóides, e a resposta tende a ser favorável..$^{53}$

Tabela 3. Graduação na doença enxerto contra hospedeiro aguda

\begin{tabular}{|c|c|c|}
\hline Grau & Classificação & Características \\
\hline 0 & $\begin{array}{l}\text { Ausência de } \\
\text { DEVH }^{*}\end{array}$ & \\
\hline I & Leve & Comprometimento inferior a $25-50 \%$ da superfície corpórea \\
\hline$\|$ & Moderado & $\begin{array}{l}\text { Alteração da pele pode variar em menos de } 25 \% \text { até a eri- } \\
\text { trodermia generalizada, o nível sérico de bilirrubinas entre } \\
2-3 \mathrm{mg} / \mathrm{dl} \text { e o volume diarréico entre } 500-1.000 \mathrm{ml} \text { ao dia }\end{array}$ \\
\hline III & Severo & $\begin{array}{l}\text { Envolvimento cutâneo de } 25-100 \% \text { da superfície corpórea, } \\
\text { níveis séricos de bilirrubina entre } 3-15 \mathrm{mg} / \mathrm{dl} \text { e volume } \\
\text { diarréico entre } 1000-1.500 \mathrm{ml} \text { ao dia }\end{array}$ \\
\hline IV & Grave & $\begin{array}{l}\text { Envolvimento cutâneo de } 25-100 \% \text { da superfície corpórea, } \\
\text { com descamação e formação de bolhas cutâneas, nível } \\
\text { sérico de bilirrubina acima de } 3 \mathrm{mg} / \mathrm{dl} \text { e volume diarréico } \\
\text { acima de } 1.000 \mathrm{ml} \text { até o aparecimento de dor abdominal e } \\
\text { íleo paralítico }\end{array}$ \\
\hline
\end{tabular}

* Doença enxerto contra hospedeiro

A primeira manifestação clínica é um exantema cutâneo que envolve, caracteristicamente, a palma das mãos e a planta dos pés. Geralmente, o eritema inicia pela face e evolui progressivamente para o restante do corpo, podendo estar acompanhado por prurido e febre. Em seguida, observam-se sintomas gastrintestinais, como diarréia profusa. $\mathrm{O}$ fígado frequentemente apresenta inflamação (o que se reflete nos testes de função hepática), pulmões e medula óssea podem também ser locais de inflamação. Citocinas são críticas para a doença e suas variantes genéticas influenciam o desenvolvimento do quadro, especialmente a IL- $10 .^{53}$

No quadro crônico, as células $\mathrm{T}$ do doador são auto-reativas especificamente contra moléculas dos antígenos de classe II e comuns ao receptor e doador. O estadiamento, por sua vez, é classificado em limitado e extenso, conforme os sistemas são afetados: pele, fígado e pulmões geralmente são acometidos (contudo, o grau de acometimento pode ser bastante variável). A DECH crônica extensa requer um prolongado regime de imunossupressão, entretanto, mais de $50 \%$ dos pacientes vão a óbito, a maioria vítimas de infecções secundárias. ${ }^{54} \mathrm{O}$ tratamento é baseado no uso de corticoides e outras drogas (ciclosporina, azatioprina, talidomida), embora a resposta possa ser insatisfatória.

Estudos recentes têm sugerido alternativas para o tratamento da $\mathrm{DECH}$, aguda ou crônica, não responsiva à terapia convencional. A experiência utilizando transplante de células-tronco mesenquimais, após o TCTH, tem evidenciado redução da ocorrência de DECH (foi encontrado, inclusive, correlação entre a precocidade do procedimento com melhores resultados). Embora parcialmente compreendido, sabe-se que as células-tronco mesenquimais são capazes de promover efeito imunomodulatório (redução de receptores de citocinas solúveis, por exemplo) em testes in vivo. A despeito disso, não foi encontrado maior recidiva da doença de base ou aumento na taxa de rejeição do enxerto. ${ }^{55,56}$

Apesar de a DECH aumentar a morbidade e a mortalidade no TMO alogênico, ela exerce um efeito antileucêmico, ou seja, 
a incidência de recidiva da doença é menor nos pacientes que apresentam essa complicação. Postula-se que a atividade de células $\mathrm{T}$ recrutadas contra os antígenos das células enxertadas promova, também, melhor controle das células leucêmicas. ${ }^{45,57}$ Nos transplantes de medula óssea, muitos estudos têm evidenciado que a histoincompatibilidade é o grande fator de risco para o desenvolvimento de DECH. ${ }^{49,58-60}$

\section{A EXPERIÊNCIA BRASILEIRA}

Criado em 2000, o Registro Brasileiro de Doadores de Medula Óssea (REDOME), reúne as informações (nome, endereço, resultados de exames, características genéticas) de pessoas que se dispõem a doar a medula óssea para transplante. Dessa forma, quando não há doador aparentado compatível, busca-se a compatibilidade num doador cadastrado.

Atualmente, há cerca de dois milhões de doadores inscritos, sendo o REDOME responsável por $70 \%$ dos transplantes no Brasil. O país possui o terceiro maior banco de dados do gênero no mundo. No Brasil, existem 70 centros para transplante de medula óssea e 20 para transplante com doadores não-aparentados.
O Instituto Nacional do Câncer realiza em média, mensalmente, dois transplantes com doadores não-aparentados e cerca de sete autólogos.

No Brasil, de outubro de 1984 a dezembro de 2010, foram realizados 1.488 transplantes. Em 2010, atingiu-se um total de 106 transplantes, número recorde desde que se iniciou a realização do procedimento pelo Instituto Nacional do Câncer.

\section{CONCLUSÃO}

Um número indefinido de pacientes sucumbe para sua doença enquanto aguarda a identificação de um doador HLA-compatível. É papel de todo médico, indubitavelmente, conhecer como funciona e para quais condições o TCTH pode beneficiar e alterar o desfecho sombrio de um grande número de pacientes. Segundo dados americanos do National Marrow Donor Program, ao redor de 30\% dos doadores registrados, identificados como doadores potenciais, não estão disponíveis para a avaliação seguinte necessária quando são contatados. Isso evidencia que o assunto carece de incentivo e ainda representa um desafio, tanto para a esfera civil e governamental, quanto para a classe médica em diversos pontos.

\section{ABSTRACT:}

Purpose: This review aimed to explore transplantation of hematopoietic stem cell in contemporary clinical practice with a multidisciplinary approach as to each medical specialty. Method: Review included books from the collection of Pontifícia Universidade Católica do Rio Grande do Sul library and research on the Medline database using the keywords: bone marrow transplantation, hematopoietic stem cells, leukemia, lymphoma, graft versus host disease, antileukemic effect, total body irradiation, histocompatibility antigens. Conclusion: Hematopoietic stem cell transplantation is a well-established practice in Medicine for decades, although there are yet many challenges that may compromise the success of such therapy - which involves the understanding to the indication, technical procedure and posttransplantation follow-up as well as to encourage the donation. Among complex issues including bioethics, immunologic and clinical, it demands knowledge from physician on the subject regardless their expertise.

Keywords: Transplantation; Hematopoietic Stem Cells; Bone Marrow; Histocompatibility Antigens; Graft vs Host Disease

\section{REFERÊNCIAS:}

1. Thomas E, Storb R, Clift RA, et al. Bone-marrow transplantation (first of two parts). N Engl J Med. 1975;292:832-43.

2. Thomas ED, Buckner CD, Banaji M, et al. Onehundred patients with acute leukemia treated by chemotherapy, total body irradiation, and allogeneic marrow transplantation. Blood. 1977;49:511-33.

3. Blume KG, Beutler E, Bross KJ, et al. Bone-marrow ablation and allogeneic marrow transplantation in acute leukemia. N Engl J Med. 1980;302:1041-6.

4. Bortin MM, Gale RP, Kay HE, et al. Bone marrow transplantation for acute myelogenous leukemia: factors associated with early mortality. JAMA. 1983;249:1166-75.

5. Speck B, Bortin MM, Champlin R, et al. Allogeneicbone-marrow transplantation for chronic myelogenous leukaemia. Lancet. 1984;1:665-8.

6. Walters MC, Patience M, Leisenring W, et al. Bone marrow transplantation for sickle cell disease. N Engl J Med. 1996;335:369-76.

7. Lucarelli G, Galimberti M, Polchi P, et al. Bone marrow transplantation in patients with thalassemia. N Engl J Med. 1990;322:417-21.

8. Storb R, Thomas ED, Buckner CD, et al. Allogeneic marrow grafting for treatment of aplastic anemia. Blood. 1974;43:157-80.

9. Gluckman E, Auerbach AD, Horowitz MM, et al. Bone marrow transplantation for Fanconi anemia. Blood. 1995;86:2856-62.
10. Buckley RH. Bone marrow reconstitution in primary immunodeficiency. Clin Immunol Principles Practice. 1995;2:1813-30.

11. Shapiro E, Krivit W, Lockman L, et al. Long-term effect of bone-marrow transplantation for childhood-onset cerebral X-linked adrenoleukodystrophy. Lancet. 2000;356:713-8.

12. Krivit W, Aubourg P, Shapiro E, et al. Bone marrow transplantation for globoid cell leukodystrophy, adrenoleukodystrophy, metachromatic leukodystrophy, and Hurler syndrome. Curr Opin Hematol. 1999;6:377-82.

13. Peters C, Shapiro EG, Krivit W. Hurler syndrome: past, present, and future. J Pediatr. 1998;133:7-9.

14. Thomas ED, Storb R, Clift RA, et al. Bone marrow transplantation. N Engl J Med. 1975: 292: 832-43.

15. Amos DB. Human histocompatibility locus HL-A. Science. 1968;159:659-60.

16. Bodmer WF. HLA: what's in a name? A commentary on HLA nomenclature development over the years. Tissue Antigens. 1997;49:293-96.

17. Dulley FL, Saboya R. Transplante de medula óssea. Disponível em: <www. medulley.com.br/docs/tmo.doc>. Acesso em: 14 ago 2011.

18. Azevedo W, Ribeiro MCC. Fontes de células-tronco hematopoéticas para transplantes. Medicina. Ribeirão Preto, 2000;33:381-9. 
19. Zago MA, Falcão RP, Pasquini R. Hematologia: fundamentos e prática. São Paulo: Atheneu. 2005. parte XXI.

20. Rizzo JD. Currents trends in BMT . ABMTR Newsletter 5:4, 1998

21. McGlave, P.B., Shu, X.O., Wen, W., et al. Unrelated donor marrow transplantation for chronic myelogenous leukaemia: 9 years experience of the national marrow donor program. Blood. 2000;95:22.

22. Champlin RE, Schimitz N, Horowitz MM, et al. Blood stem cells compared with bone marrow as a source of hematopoietic cells for allogeneic transplantation. Blood. 2000;95:3702-9.

23. Vigorito AC, Azevedo WM, Marques JFC, et al. A randomised, prospective comparison of allogeneic bone marrow and peripheral blood progenitor cell transplantation in the treatment of haematological malignancies. Bone Marrow Transplant. 1998;22:1145-51.

24. Heldal D, Tjonnfjord G, Albrechtsen D, et al. A randomised study of allogeneic transplantation with stem cells from blood or bone marrow. Bone Marrow Transplant. 2000;25:1129-36.

25. Azevedo WM, Aranha FJ, Gouveia JV, et al. Allogeneic transplantation with blood stem cells mobilized by rh- GCSF for haematological malignancies. Bone Marrow Transplant. 199516:647-53.

26. Russell JA, Larrat L, Brown C, et al. Allogenic blood stem cell and bone marrow transplantation for acute myelogenous leukemia and mielodysplasia: influence of stem cell source on outcome. Bone Marrow Transplant. $1999 ; 24: 1177-83$

27. Przepiorka D, Smith TL, Follodn J, et al. Risk factors for acute graftversus-host disease after allogeneic blood stem cell transplantation. Blood. 1999;94:1465-70

28. Wagner JE, Rosenthal J, Sweetman R, et al. Successful transplantation ofHLA-matched and HLAmismatched umbilical cord blood from unrelated donors: analysis of engraftment and acute graftversus- host disease. Blood. 1996;88:795-802.

29. Kurtzberg J, Laughlin M, Graham ML, et al. Placental blood as a source of hematopoietic stem cells for transplantation into unrelated recipients. N Engl J Med. 1996;335:157-66.

30. Gluckman E, Rocha V, Boyer-Chammard A, et al. Outcome of cord-blood transplantation from related and unrelated donors: Eurocord Transplant Group and the European Blood and Marrow Transplantation Group. N Engl J Med. 1997;337:373-81.

31. Rubinstein P, Carrier C, Scaradavou A, et al. Outcomes among 562 recipients of placental-blood transplants from unrelated donors. $\mathrm{N}$ Engl J Med. 1998;339:1565-77.

32. Thomson BG, Robertson KA, Gowan D, et al. Analysis of engraftment, graft-versus-host disease, and immune recovery following unrelated donor cord blood transplantation. Blood. 2000;96: 2703-11.

33. Rocha V, Cornish J, Sievers EL, et al. Comparison of outcomes of unrelated bone marrow and umbilical cord blood transplants in children with acute leukemia. Blood. 2001;97:2962-71.

34. Locatelli F, Rocha V, Chastang C, et al. Factors associated with outcome after cord blood transplantation in children with acute leukemia: EurocordCord Blood Transplant Group. Blood. 1999;93:3662-71.

35. Laughlin MJ, Barker J, Bambach B, et al. Hematopoietic engraftment and survival in adult recipients of umbilical- cord blood from unrelated donors. N Engl J Med. 2001;344:1815-22.

36. Barker JN, Davies SM, DeFor T, et al. Survival after transplantation of unrelated donor umbilical cord blood is comparable to that of human leukocyte antigen-matched unrelated donor bone marrow: results of a matched-pair analysis. Blood. 2001;97:2957-61.

37. Wagner JE, Barker JN, DeFor TE, et al. Transplantation of unrelated donor umbilical cord blood in 102 patients with malignant and nonmalignant diseases: influence of CD34 cell dose and HLA disparity on treatmentrelated mortality and survival. Blood. 2002;100:1611-18.

38. Copelan EA. Medical progress: hematopoietic stem-cell transplantation. N Engl J Med 2006: 354(17):1813-26.
39. Howe CW, Radde-Stepaniak T. Hematopoietic cell donor registries. In: Thomas E, Blume KG, Forman SJ, eds. Hematopoietic Cell Transplantation, 2nd ed. Malden, MA: Blackwell Science. 1999:503-14.

40. Rachmilewitz EA, Giardina PJ. How I treat thalassemia. Blood. 2011 Aug 2 [Epub ahead of print].

41. Voltarelli JC, Stracieri ABPL. Aspectos imunológicos dos transplantes de células-tronco hematopoéticas. Medicina, Ribeirão Preto, 33: 443-462, out./ dez. 2000

42. Hamerschlak N, Rodrigues M, Moraes DA, Oliveira MC, Stracieri AB, Pieroni $\mathrm{F}$, et al. Brazilian experience with two conditioning regimens in patients with multiple sclerosis: BEAM/horse ATG and CY/rabbit ATG. Bone Marrow Transplant. 2010 Feb;45(2):239-48. Epub 2009 Jul 6.

43. Böttcher S, Ritgen M, Dreger P. Allogeneic stem cell transplantation for chronic lymphocytic leukemia: lessons to be learned from minimal residual disease studies. Blood Rev. 2011;25(2):91-6.

44. Servais S, Baron F, Beguin Y. Allogeneic hematopoietic stem cell transplantation (HSCT) after reduced intensity conditioning. Transfus Apher Sci. 2011;44(2):205-10.

45. Hoffbrand AV, Mossa PAH, Pettit JE. Essential Haematology. Massachusetts, USA: Blackwell Publishing, 5 ed. 2006

46. Bathia S. Long-term health impacts of hematopoietic stem cell transplantation inform recommendations for follow-up. Expert Rev Hematol. 2011;4(4):43754

47. Appelbaum FR. The current status of hematopoietic cell transplantation. Annu Rev Med. 2003:54; 91-512.

48. Peggs KS, Mackinnon S. Immune reconstitution following haematopoietic stem cell transplantation. Br J Haematol. 2004:124;407-20.

49. Ferrara JL, Deeg HJ. Graft-versus-host disease. N Engl J Med. 1991;324:66774.

50. Horowitz SD, Bach FH, Groshong T, Hong R, Yunis EJ. Treatment of severe combined immunodeficiency with bone-marrow from an unrelated, mixedleucocyte-culture-non-reactive donor. Lancet. 1975;2:431-3.

51. Lohrmann HP, Dietrich M, Goldmann SF, et al. Bone marrow transplantation for aplastic anaemia from a HL-A and MLC- identical unrelated donor. Blut. 1975;31:347-54

52. Speck B, Zwaan FE, van Rood JJ, Eernisse JG. Allogeneic bone marrow transplantation in a patient with aplastic anemia using a phenotypically HLA-identifcal unrelated donor. Transplantation. 1973;16:24-8.

53. Neumann J, Filho MA, Garcia VD. Transplante de órgãos e tecidos. São Paulo: Segmento Farma, 2006.

54. Ho VT, Soiffer RJ. The history and future of T-cell depletion as graftversus-host disease prophylaxis for allogeneic hematopoietic stem cell transplantation. Blood. Dez 2001:98:3192-204.

55. Ringden O, Le Blanc K. Mesenchymal stem cells for treatment of acute and chronic graft-versus-host disease, tissue toxicity and hemorrhages. Best Pract Res Clin Haematol. 2011 Mar;24(1):65-72. Epub 2011 Feb 25.

56. Ringdén O, Uzunel M, Rasmusson I, Remberger M, Sundberg B, Lönnies $\mathrm{H}$, et al. Mesenchymal stem cells for treatment of therapy-resistant graftversus-host disease. Transplantation. 2006 May 27;81(10):1390-7.

57. Roncarolo MG, Gregori S, Lucarelli B, et al. Clinical tolerance in allogeneic hematopoietic stem cell transplantation. Immunol Rev. 2011;24(1):145-63

58. Beatty PG, Clift RA, Mickelson EM, et al. Marrow transplantation from related donors other than HLA-identical siblings. N Engl J Med. $1985 ; 313: 765-71$.

59. Petersdorf EW, Gooley TA, Anasetti C, et al. Optimizing outcome after unrelated marrow transplantation by comprehensive matching of HLA class I and II alleles in the donor and recipient. Blood. 1998;92:3515-20.

60. Benjamin JE, Gil S, Negrin RS. Biology and clinical effects of natural killer cells in allogeneic transplantation. Curr Opin Oncol. 2010;22(2):130-7. 